\title{
Sialic acid changes in Dalton's lymphoma-bearing mice after cyclophosphamide and cisplatin treatment
}

B.M. Nicol and S.B. Prasad

\author{
Cell and Tumour Biology Laboratory, Department of Zoology, \\ School of Life Sciences, N orth-Eastern Hill University, Shillong, India
}

\begin{abstract}
Correspondence

S.B. Prasad

Cell and Tumour Biology Laboratory

Department of Zoology

School of Life Sciences

North-Eastern Hill University

Shillong-793 022

India

Fax: +91-364-55-0076/55-0108

E-mail: sbpnehu@ hotmail.com or

sbprasad@ nehu.ac.in

Research supported by North-Eastern Hill University, Shillong and

University Grants Commission (under DRS, COSIST programme), New

Delhi.

Received June 20, 2001

Accepted March 6, 2002

Sialic acid changes in Dalton's lymphoma cells and other tissues of 10-12-week-old Swiss albino mice were investigated in relation to tumour growth in vivo and following cyclophosphamide (ip, $200 \mathrm{mg} /$ $\mathrm{kg}$ body weight) or cisplatin (ip, $8 \mathrm{mg} / \mathrm{kg}$ body weight) treatment. Three to four animals of both sexes were used in each experimental group. The sialic acid level of tumour cells $(0.88 \mu \mathrm{mol} / \mathrm{g})$ increased with tumour progression $(1.44-1.59 \mu \mathrm{mol} / \mathrm{g} ; \mathrm{P} \leq 0.05)$ in mice. Sialic acid concentration in other tissues (liver, kidney, testes and brain) also increased $(\sim 40,10,30$ and $58 \%$, respectively) in the tumour-bearing hosts as compared with that in the respective tissues of normal mice. In vivo cyclophosphamide or cisplatin treatment resulted in an overall decrease of sialic acid contents in the tissues. Cyclophosphamide was more efficient in lowering tissue sialic acid than cisplatin $(\mathrm{P} \leq 0.01$, ANOVA). It is suggested that sialic acid residues could be an important factor contributing to the manifestation of malignant properties in cancer cells in general and Dalton's lymphoma cells in particular. A significant decrease in the sialic acid content of Dalton's lymphoma cells after cisplatin or cyclophosphamide treatment may bring about specific changes in tumour cells which could be associated with tumour regression.
\end{abstract}

Cyclophosphamide (2-[bis-/2-chloroethyl-amino]-tetrahydro-2H-1,2,3-oxazaphosphorine-2-oxide) is an alkylating chemotherapeutic drug used against a wide spectrum of malignancies which include leukemia, breast cancer, lymphoma, lung cancer, prostate cancer and ovarian cancer (1). The cytotoxicity induced by cyclophosphamide is directly connected with its metabolism and toxic reactions of its metabolites. The parent compound is inactive in vitro and in vivo. Activation of cyclophosphamide by the cytochrome P450 system predominantly in the liver generates the active alkylating metabolites, the most important being phosphoramide mustard (2). The alkylating metabolite(s) can bind to a variety of molecules including amino acids, proteins and peptides, but the most important binding site is DNA where cross-linking occurs. This can lead to DNA strand breaks, cessation of DNA synthesis, inhibition of cell proliferation, and ultimately to cell death (3). Cisplatin (cisdiamminedichloroplatinum-II) is one of the 
leading chemotherapeutic drugs being used effectively against various malignancies $(4,5)$. It has been reported that cisplatin has an effect on the surface of the cells, and brings about definite changes in cell lectin agglutinability and in the topographical pattern of lectin-binding sites on the cell surface (6).

Sialic acids are derived from neuraminic acid whose main derivative is $\mathrm{N}$-acetylneuraminic acid which is generally used as the synonym for sialic acid (7). Sialic acids are widely distributed in nature as non-reducing termini of glycoproteins and glycolipids. The presence of sialic acids has been reported in some viruses, bacteria, plants, different invertebrates and all vertebrate tissues (8). About $70 \%$ of the total sialic acids of eukaryotic cells are found on the cell surface and the remainder is distributed among the endoplasmic reticulum, mitochondria, lysosomes, etc. (8). Because of their acidic nature, they impart a negative charge to the cell surface and are important in cellto-cell or cell-to-matrix interactions. Sialic acid residues on the cell surface may also be involved in the masking of cell surface antigens and may act as receptors for lectins, virus particles, some hormones and antibodies (9). There is a large body of evidence suggesting that the surface properties of tumour cells differ from those of their normal counterparts and that these changes are due in part to altered sialoglycoconjugates expressed on the plasma membrane (10). It has been reported that with the progression of tumour development there is an increase in sialic acid content of Yoshida ascites sarcoma cells (11). Although elevated levels of sialic acid have been often associated with malignancy (12), a clear correlation of changes in sialic acid concentrations and malignancy has not emerged, because some reports (13) have shown a decrease and not an increase in sialic acid in association with malignancy. Thus, evaluation of sialic acid changes could be very helpful by contribut- ing both to the diagnosis of patients and to monitoring their progression and response to treatment.

In view of the importance of sialic acid in the manifestation of the biological properties of malignant cells, the present studies were undertaken to elucidate quantitative changes in sialic acid ( $N$-acetylneuraminic acid) during ascites Dalton's lymphoma tumour progression and after treatment with cyclophosphamide and cisplatin to illustrate the comparative effects of these drugs on the sialic acid content of various host tissues.

Ascites Dalton's lymphoma was maintained in vivo in 10-12-week-old inbred Swiss albino mice by serial intraperitoneal (ip) transplantations of $1 \times 10^{7}$ tumour cells per animal $(0.25 \mathrm{ml}$ volume in PBS). PBS was prepared by adding $0.15 \mathrm{M} \mathrm{NaCl}$ to $0.01 \mathrm{M}$ sodium phosphate buffer, and $\mathrm{pH}$ was adjusted to 7.4. Tumour-transplanted hosts usually survived for 20-22 days.

The cyclophosphamide (14) and cisplatin (4) doses used were 200 and $8 \mathrm{mg} / \mathrm{kg}$ body weight, respectively, for the treatment of tumour-bearing mice. A single dose of cyclophosphamide or cisplatin was administered ip to tumour-bearing mice on the 10th day post-tumour transplantation which is approximately the mid period of tumour growth. After 24, 48, 72 and $96 \mathrm{~h}$ of treatment (i.e., on the 11 th, 12th, 13th and 14th day posttumour transplantation) liver, kidney, testes, brain and ascites tumour were collected. The same tissues were also collected from the control tumour-bearing mice which had been injected with the same volume of $0.89 \%$ $\mathrm{NaCl}$. Ascites tumour was centrifuged ( 800 $\mathrm{g}, 10 \mathrm{~min}$, at $4^{\circ} \mathrm{C}$ ) to separate the tumour cell pellet. Liver, kidney, testes and brain were also collected from normal animals bearing no tumour and injected with $0.89 \% \mathrm{NaCl}$ only. The drug treatments and sialic acid determinations were repeated independently 3-4 times.

The ascites tumours collected from mice under different experimental conditions were 
centrifuged $\left(800 \mathrm{~g}, 10 \mathrm{~min}, 4^{\circ} \mathrm{C}\right)$ to obtain tumour cell pellets. The tumour cell pellets and other tissues were homogenized in $0.1 \mathrm{~N}$ $\mathrm{H}_{2} \mathrm{SO}_{4}(1.0 \mathrm{ml} / 10 \mathrm{mg}$ tissue $)$ and incubated in a water bath at $80^{\circ} \mathrm{C}$ for $1 \mathrm{~h}$ with intermittent shaking. The resulting suspensions were centrifuged $(800 \mathrm{~g}, 10 \mathrm{~min})$ and the sialic acid contents were estimated in the supernatants by the method of Warren (15).

Sialic acids terminate oligosaccharide chains in the mammalian glycoconjugates and play a key role in the normal functions of these glycoconjugates. It has been reported that sialic acid could be used as a sensitive biomarker for lung cancer although their specificity is low (16). However, a definite correlation of the changes in sialic acid concentration with malignancy has not been reported because of various reports indicating an increase (12) or a decrease (13) of sialic acid in different malignancies. The present findings showed an increase in sialic acid concentrations in Dalton's lymphoma cells with tumour growth in mice (Figure 1), which may be an important feature of this tumour. The increase of sialic acid in Dalton's lymphoma cells may be due to enhanced activity of enzymes involved in sialic acid synthesis and/or transfer. Some reports have indicated a 3-5 times increased sialyl transferase activity in various virally transformed cells as compared to the corresponding normal cells, an event that may be associated with the increase in the amount of sialic acid in the transformed cells (13). The elevated sialic acid levels in malignant cells have also been observed for murine Yoshida ascites sarcoma (11). The influence of sialic acid on the oncogenicity of tumour cells may be based on i) a negative charge determining constituent on the cell surface, resulting in the loss of contact inhibition, ii) an antigenmasking agent, and iii) a component of the cell surface involved in the adherence of tumour cells to the mesothelial membrane prior to their dissemination to form metastases (9).
In our experiments, the determination of sialic acid in other tissues revealed that sialic acid content was much higher in brain $(\sim 3$ $\mu \mathrm{mol} / \mathrm{g})$ than in liver, kidney and testes $(\sim 1$ $\mu \mathrm{mol} / \mathrm{g}$ ) (Table 1). It was noted that sialic acid content increased in the tissues of tumour-bearing mice when compared with the respective tissue of normal mice (Table 1). This increase in sialic acid content was higher in the brain $(\sim 58 \%)$, liver $(\sim 40 \%)$ and testes $(\sim 30 \%)$ than in the kidney $(\sim 10 \%)$ (Table 1$)$. In many diseases such as Salla disease, free sialic acid storage disease, and sialuria, an increased concentration of free sialic acid in various tissues and fluids has been observed which may be due at least in part to defective de novo synthesis, transport, storage, catabolism, excretion and/or metabolic regulation of sialic acid in the cells (17), and a similar activity may have been involved here in Dalton's lymphoma-bearing mice also. Furthermore, the observation of increased sialic acid content in the tissues of tumourbearing mice could be helpful for Dalton's lymphoma cells in the host since sialic acid has also been known to be important in the transport of proteins, amino acids and ions to the cancer cells (10). Therefore, it was quite natural to evaluate the activities of some anticancer agents in terms of their effects on the changes in sialic acid levels of tissues as well as Dalton's lymphoma cells of tumourbearing mice. For this purpose, in the present study cisplatin and cyclophosphamide were

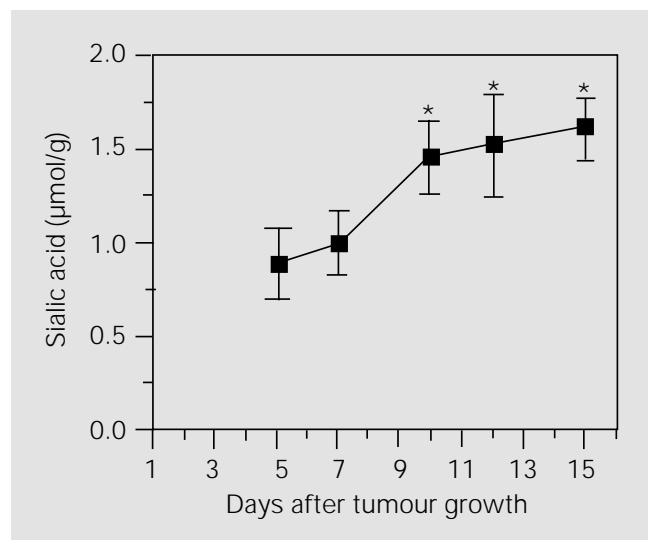

Figure 1. Changes in the sialic acid content of Dalton's lymphoma cells with growth of the tumour in mice. Data are reported as means $\pm S D(N=4)$. $* \mathrm{P}<0.05$ compared to the 5th day of tumour growth (Student t-test). 
Table 1. Quantitative changes in the sialic acid content of different tissues of Dalton's lymphoma-bearing mice after cisplatin or cyclophosphamide treatment.

\begin{tabular}{|c|c|c|c|c|c|}
\hline Treatment & Liver & Kidney & $\mathrm{DL}$ & Testes & Brain \\
\hline Normal mice & $1.031 \pm 0.047$ & $1.078 \pm 0.158$ & - & $0.786 \pm 0.155$ & $3.213 \pm 0.243$ \\
\hline $\begin{array}{l}\text { Tumour-bearing } \\
\text { (control) }\end{array}$ & $1.482 \pm 0.051$ & $1.183 \pm 0.141$ & $1.441 \pm 0.207$ & $1.053 \pm 0.077$ & $5.083 \pm 0.344$ \\
\hline Cisplatin (24 h) & $1.340 \pm 0.071^{* *}$ & $1.233 \pm 0.187$ & $1.562 \pm 0.249$ & ND & $5.214 \pm 0.437$ \\
\hline Cisplatin (48 h) & $1.264 \pm 0.141^{*}$ & $1.038 \pm 0.114$ & $1.372 \pm 0.120$ & ND & $4.286 \pm 0.229 *$ \\
\hline Cisplatin (72 h) & $1.493 \pm 0.204$ & $1.694 \pm 0.258^{* *}$ & $1.142 \pm 0.101^{* *}$ & ND & $3.400 \pm 0.295^{* *}$ \\
\hline Cisplatin (96 h) & $1.138 \pm 0.122^{* *}$ & $0.988 \pm 0.139$ & $1.014 \pm 0.076^{* *}$ & ND & $2.257 \pm 0.178^{\#}$ \\
\hline CP (24 h) & $0.985 \pm 0.214^{+}$ & $0.859 \pm 0.085^{* *}$ & $1.091 \pm 0.175^{*}$ & $0.818 \pm 0.149 *$ & ND \\
\hline CP (48 h) & $0.961 \pm 0.110^{+}$ & $0.872 \pm 0.180^{*}$ & $1.046 \pm 0.182 *$ & $0.890 \pm 0.181$ & ND \\
\hline CP (72 h) & $1.213 \pm 0.139 * *$ & $1.107 \pm 0.042$ & $1.087 \pm 0.184^{*}$ & $0.894 \pm 0.135$ & ND \\
\hline CP (96 h) & $1.067 \pm 0.088^{* *}$ & $1.012 \pm 0.061$ & $1.031 \pm 0.149 * *$ & $0.887 \pm 0.216$ & ND \\
\hline
\end{tabular}

Sialic acid content is reported as $\mu \mathrm{mol} / \mathrm{g}$ wet weight. Data are reported as means $\pm S D(N=3-4)$.

${ }^{*} \mathrm{P}<0.10,{ }^{*} * \mathrm{P}<0.05,+\mathrm{P}<0.02$, and ${ }^{\mathrm{P}} \mathrm{P}<0.01$ compared with the respective tumour-bearing control. The significance of variations between controls, cisplatin treatments (ip, $8 \mathrm{mg} / \mathrm{kg}$ body weight) and CP treatments (ip, $200 \mathrm{mg} / \mathrm{kg}$ body weight) in a tissue was tested by ANOVA $(\mathrm{P}<0.01)$. CP = cyclophosphamide; $\mathrm{DL}=$ Dalton's lymphoma; ND = not determined.

used as the anticancer agents. Cisplatin or cyclophosphamide treatment of Dalton's lymphoma-bearing mice causes tumour regression, suggesting an effective anticancer activity of these drugs in this murine tumour model (Prasad SB and Nicol BM, unpublished results). Although the ability of these drugs to interact with cellular DNA has been suggested to be the primary target in the mechanism of their anticancer activity $(3,4)$, the association of additional components such as biochemical/enzymatic changes, cell surface, immune response of the cells/host is also known (6) and has led to the proposition of the involvement of multistep/multilevel effects in the hosts during cisplatin-mediated cancer chemotherapy (5). As far as their effects on quantitative changes in sialic acids of Dalton's lymphoma cells and tissues is concerned, it was noted that cyclophosphamide or cisplatin treatment of tumour-bearing mice for 24-96 h caused a decrease of sialic acid in the tissues (Table 1). The decrease of sialic acid contents after cisplatin treatment was noted to be predominant in the brain. Furthermore, a comparative analysis of the effect of these two drugs revealed that the sialic acid decrease in cyclophosphamide-treated tissues was more marked than the decrease in cisplatin (Table $1, \mathrm{P} \leq 0.01$, ANOVA) which suggests that sialic acid decrease may be playing a more substantial role in the cyclophosphamide-mediated antitumour effect than in the cisplatin-mediated effect. About $70 \%$ of total sialic acid is generally found on the cell surface (8) and the decrease of sialic acid in Dalton's lymphoma cells after cyclophosphamide or cisplatin treatment may be associated with an enhancement of the immune response of the host. It has been suggested that the loss of sialic acid should lower the negative surface charge and may lead to increased cell deformity and to enhanced cell susceptibility to phagocytosis (18). It has been suggested that although sialic acid itself is not antigenic, it may control the expression of surface antigens, and sialic acid release from tumour cells after cisplatin treatment may cause the possible exposure of certain antigenic sites on the tumour cell surface (19). In fact, other studies have also shown that specific release of sialic acid after neuraminidase treatment of many tumour cells such as Landschutz 
ascites tumour, L1210 tumour, methylcholanthrene-induced fibrosarcoma, and 6C3 HED lymphosarcoma resulted in increased immunogenicity (20) and a reduced capacity of tumour cells to proliferate in vivo. Along with the sialic acid decrease in Dalton's lymphoma cells this drug-mediated decrease of tissue sialic acid in tumour-bearing mice should also bring their functional activity to normal in the hosts, thereby facilitating tumour regression.

Thus, the present findings suggest that sialic acid changes in tumour cells and tissues could be an important step during tumour growth/malignancy as well as tumour regression after cisplatin or cyclophosphamide treatment and they support the view of multilevel/multistep effects of the drugs in cancer chemotherapy.

\section{Acknowledgments}

We thank Prof. S.K. Mishra and Dr. N.P. Goel for help with some calculations.

\section{References}

1. Black DJ \& Livingston RB (1990). Antineoplastic drugs in 1990 - a review (Part I). Drugs, 39: 489-501.

2. Friedman OM, Wodinsky I \& Myles A (1976). Cyclophosphamide-related phosphoramide mustards: recent advances and historical perspective. Cancer Treatment Reports, 60: 337-346.

3. Wang J Y, Prorok G \& Vaughan WP (1993). Cytotoxicity, DNA-cross linking, and DNA single-strand breaks induced by cyclophosphamide in a rat leukemia in vivo. Cancer Chemotherapy and Pharmacology, 31: 381-386.

4. Rosenberg B (1985). Fundamental studies with cisplatin. Cancer, 55: 2303-2316.

5. Prasad SB \& Giri A (1994). Antitumour effect of cisplatin against murine ascites Dalton's lymphoma. Indian J ournal of Experimental Biology, 32: 155-162.

6. Prasad SB \& Sodhi A (1982). Effect of cisdichlorodiammine platinum (II) on surface of tumor and normal cells: biochemical, fluorescence and electron microscopical studies. Indian J ournal of Experimental Biology, 20: 559-571.

7. Ledeen RW \& Yu RK (1976). Chemistry and analysis of sialic acid. In: Rosenberg $A \&$ Schengrund C (Editors), Biological Roles of Sialic Acid. Plenum Press, New York, NY, USA, 1-57.

8. Warren $L$ (1976). The distribution of sialic acids within the eukaryotic cell. In: Rosenberg A \& Schengrund C (Editors), Biological Roles of Sialic Acid. Plenum Press,
New York, NY, USA, 103-121.

9. J eanloz RW \& Codington J F (1976). The biological role of sialic acid at the surface of the cell. In: Rosenberg A \& Schengrund $C$ (Editors), Biological Roles of Sialic Acid. Plenum Press, New York, NY, USA, 201238.

10. McDonagh J C \& Nathan RD (1990). Sialic acid and the surface charge of delayed rectifier potassium channels. J ournal of Molecular and Cellular Cardiology, 22: 1305-1316.

11. Rao VS \& Sirsi M (1973). Studies on sialic acid in Yoshida ascites sarcoma cells. Indian J ournal of Biochemistry and Biophysics, 10: 37-41.

12. Ingraham HA \& Alhadeff J A (1978). Characterization of sialyl-transferase in noncancerous and neoplastic human liver tissue. J ournal of the National Cancer Institute, 61: 1371-1374.

13. Onodera $K$, Yamaguchi $N$, Kuchino $T \&$ Aoi Y (1976). Alterations in surface glycoproteins and level of sialyltransferase of cells transformed by a temperature-sensitive mutant of SV40. Proceedings of the National Academy of Sciences, USA, 73: 4090-4094.

14. Czyzewska A \& Mazur L (1995). Suppressing effect of WR-2721 on micronuclei induced by cyclophosphamide in mice. Teratogenesis, Carcinogenesis, and $\mathrm{Mu}$ tagenesis, 15: 109-114.

15. Warren L (1959). The thiobarbituric acid assay of sialic acid. J ournal of Biological
Chemistry, 234: 1971-1975.

16. Kakari S, Stringou E, Toumbis M, Ferderigos AS, Poulaki E, Chondros $K$, Dema A, Kotsovoulou V \& Pavlidis N (1991). Five tumour markers in lung cancer: significance of total and lipid-bound sialic acid. Anticancer Research, 11: 21072110.

17. Thomas GH, Scocca J, Miller CS \& Reynolds LW (1985). Accumulation of Nacetylneuraminic acid (sialic acid) in human fibroblasts cultured in the presence of $\mathrm{N}$-acetylmannosamine. Biochimica et Biophysica Acta, 846: 37-43.

18. Simmons RL \& Rios A (1972). Modification of immunogenicity in experimental immunotherapy and prophylaxis. In: Day SB \& Good RA (Editors), Membranes and Viruses in Immunopathology. Academic Press, New York, NY, USA, 563-576.

19. Sama S, Bhola RK \& Sodhi A (1988). Release of protein bound sialic acid from fibrosarcoma cells after cis dichlorodiammineplatinum(II) treatment: the possible role in tumour regression. Polish J ournal of Pharmacology and Pharmacy, 40: 73-80.

20. Bekesi J G, Roboz J P \& Holland J F (1976). Characteristics of immunity induced by neuraminidase-treated lymphosarcoma cells in $\mathrm{C}_{3} \mathrm{H}\left(\mathrm{MTV}^{+}\right)$and $\mathrm{C}_{3} \mathrm{H}\left(\mathrm{MTV}^{-}\right)$mice. Israel J ournal of Medical Sciences, 12: 288-303. 